\title{
Bacterial Pathogens and their Susceptibility to Antibiotics among Mothers with Premature Rupture of Membranes at a Teaching Hospital in Western Uganda.
}

\section{Simon Byonanuwe ${ }^{1^{*}}$ | Emmanuel Nzabandora ${ }^{1}$ | Baltazar Nyongozi ${ }^{1}$ | Theophilus Pius ${ }^{2}$ \\ | Yarine Fajardo ${ }^{1} \mid$ Robinson Ssebuufu ${ }^{3}$}

${ }^{1}$ Department of Obstetrics and Gynaecology, Kampala

International University Teaching Hospital, Uganda

${ }^{2}$ Department of Medical Laboratory Science, Kampala International University Teaching Hospital, Uganda

${ }^{3}$ Department of Surgery, Kampala International University Teaching Hospital, Uganda

\begin{abstract}
Background: Premature rupture of membranes (PROM) remains a great burden to mothers and their unborn children all over the world with several adverse maternal and fetal outcomes. This study aimed at determining common bacterial pathogens and their susceptibility patterns in women with PROM at Kampala International University Teaching Hospital (KIU-TH).
\end{abstract}

Methods: This was a cross-sectional study conducted in the months of September 2019 to November 2019. A total of 334 pregnant mothers above 28 weeks of pregnancy admitted in maternity ward of KIU-TH were consecutively enrolled. Interviewer administered questionnaires and laboratory forms were used to collect data. Endocervical swabs were obtained from those with PROM and taken to the laboratory for culture and susceptibility tests. Descriptive statistics were used using STATA 14.2 .

Results: 46 (13.8\%) mothers had PROM. Of these, the most common bacterial pathogens identified were $S$. aureus (29.6\%), E. coli $(25.9 \%)$ and N. gonorrhoeae (25.9\%). Antibacterial susceptibility tests revealed highest sensitivity to imipenem $(100 \%)$, nitrofurantoin $(92.6 \%)$, cloxacillin $(85.2 \%)$ and azithromycin $(81.5 \%)$. Total resistance to amoxacillin, ceftriaxone and ampicillin was found.

Conclusion: Women with PROM predominatly have Staphylococcus aureus, Escherichia coli and Neisseria gonorrhoeae. Imipenem, nitrofurantoin, cloxacillin and azithromycin are the most effective antibiotics among patients with PROM.

Keywords: Common bacterial pathogens, Premature rupture of membranes, Susceptibility patterns. 


\section{1 | INTRODUCTION:}

$\mathrm{P}$ ROM continues to be a serious threat to pregnancy globally, with several devastating complications before, during and after delivery for both the mother and her baby. It affects about 5 to $15 \%$ of all pregnancies worldwide (1). Up to $50 \%$ preterm births and $80 \%$ clinical and subclinical maternal infections are associated with PROM worldwide with a four-fold increased risk of fetal mortality (2)(3). An estimated 65 perinatal deaths per 1000 live births following PROM have been reported in Mulago hospital in Uganda (4). There is strong epidemiological and biochemical evidence which links PROM to ascending infection of the female genital tract. Bacteria are thought to elicit release of inflammatory substances which in turn stimulate the production of prostaglandins leading to PROM. Bacteria are also able to produce a number of proteolytic enzymes such as collagenese, elastase, and gelatinase which can cause local weakening of the fetal membranes. Bacterial infection is also a common complication of PROM as a result of ascent of the microbes from the lower genital tract which may result in chorioamnionitis as well as puerperal and/or neonatal infections.

There is a growing concern over antimicrobial resistance which is currently estimated to account for more than 700,000 deaths per year worldwide (5). In Africa, resistance to commonly used antibiotics has greatly increased over the last 20 years. According to a situation analysis report on antibiotic resistance by the Uganda National Academy of Sciences (2015), there is a significant cumulative increase in microbial resistance to antibiotics. In some places for example, the prevalence of resistance to some antibiotics is approaching or already at $100 \%$ (6). Recent studies have expressed concern over uncertainty about the choice of antibiotics for prophylaxis in women with premature rupture of membranes. It is ideal therefore, that culture and susceptibility patterns are done to ascertain the choice of antibiotics for use in these patients. However, because of limited access to the potential laboratory services in Uganda, coupled with the long time between the tests and the outcomes (minimum of four days at KIU-TH), broad spectrum antibiotics are given empirically.
The Uganda clinical guidelines recommend a combination of oral erythromycin $(250 \mathrm{mg})$ and amoxicillin (500mg) for prophylaxis against ascending genital tract infection following PROM (7). It is possible however that the associated organisms have changed, developed resistance, or vary with this particular area of study. This study therefore sought to provide information about the common bacterial pathogens and the choice of antibiotics for prophylaxis against ascending infection following PROM and hence contribute to the generation of evidence based institutional protocols for treatment of mothers with PROM in this area.

\section{2 | MATERIALS AND METHODS:}

The study was conducted in maternity ward of KIU-TH, a private not for profit teaching hospital for Kampala International University located in Bushenyi district in south-western Uganda about 370 kilometers from the center of Kampala city. This is a specialized hospital offering both out-patient and in-patient services with a 700 bed capacity. KIU$\mathrm{TH}$ has a fully functional modern referral laboratory with a well-equipped microbiology laboratory and specialized staff. A cross-sectional design was used. The study was carried out over a period of three months, in the months of September 2019 to November 2019 which, among others, aimed to determine the common bacterial pathogens and their antibacterial susceptibility patterns in pregnant mothers with PROM. All pregnant mothers both adults and emancipated minors above 28 weeks of gestation admitted in maternity ward that consented to participate in the study were included in the study since other aspects such as prevalence were also being jointly analyzed.

Supplementary information The online version of this article (https://doi.org/10.15520/mcrr.v3i7.106) contains supplementary material, which is available to authorized users.

Corresponding Author: Simon Byonanuwe

Department of Obstetrics and Gynaecology, Kampala International University-Western Campus, P.O.Box 71, Bushenyi, Uganda 


\section{MANUSCRIPT CENTRAL}

Pregnant mothers with mental illness and those who were unconscious at the time of admission were excluded because it was not possible to interview them since the study was also linked to a wider aspect of ascertaining the predictive factors for PROM. Sample size was determined using Daniel's formula (8). A total of 365 mothers above 28 weeks of pregnancy were admitted on ward throughout the study period. Of these, 29 opted out for the study after they were educated and counseled for the study. Two mothers; one with mental illness and another one who was unconscious at the time of her admission on the ward were excluded from the study as it was not possible to interview them. These proceeded with routine assessment and treatment on ward. All the other 334 patients above 28 weeks of pregnancy were enrolled into the study and underwent a data collection process. This was basically our denominator to partly enable us ascertain the prevalence of PROM at this hospital as well. However, only the women who were finally proven to have premature rupture of membranes had samples removed for culture and susceptibility test. Women with history of antibiotic treatment within the past two weeks of onset of draining of liquor per vagina were also meant to be excluded at this point. However our assessment revealed no one.

\section{3 | STUDY PROCEDURE:}

regnant mothers who met the inclusion criteria for this study were consecutively enrolled until the target population was reached. The mothers were received and or reviewed (for those already admitted) by the principle investigator. They were educated and counseled about the study and a written consent obtained for those who opted to participate in the study. An investigator administered questionnaire was then administered, history taken and physical examination done. Clinical diagnosis of premature rupture of membranes was made as recommended by the Royal College of Obstetricians and Gynaecologists' GreenTop guideline number 73 (9). For a mother with history suggestive of spontaneous rupture of membranes, using an aseptic technique, under sufficient light, a sterile Cusco's bivalve self-retaining vaginal speculum was placed. Visualization of pooling of fluid in the posterior vaginal fornix of the patient was considered to have premature rupture of the membranes. Participants confirmed to have leakage of liquor via the cervix had endocervical swabs taken. A sterile swab clearly labeled with the participant's study number was inserted into the endocervix and left for two seconds. It was then removed carefully to avoid contact with the vaginal mucosa so as to minimize the risk of contamination with the vaginal flora. The sample was immediately placed in a sterile swab container and transported immediately to the microbiology laboratory for analysis. In the laboratory, the sample was immediately inoculated in the primary culture media: Blood agar, Chocolate agar and MaCconkey agar; Gram staining was done, as well as the different biochemical tests to isolate the different bacterial pathogens. Susceptibility tests were done according to the World Health Organization recommended Kirby-Bauer technique.

\section{Sample processing}

This was achieved through the following steps using standard laboratory protocols:

Gram staining and microscopy: A smear was made for Gram stain and microscopy. A drop of physiological saline was added on the center of a clean dried glass slide and the swab containing the sample rolled in the drop of physiological saline spreading it on the glass slide in a circular motion to make a thin smear. The smear was allowed to air dry and then heat fixed by passing it at least three times over a flame. The slide was placed on the staining rack and flooded with crystal violet solution for 60 seconds, washed with clean water and covered with lugol's Iodine (mordant); then allowed to act for a minute. The slide was again washed in clean water and then decolorized with $50 \%$ acetone alcohol. It was then washed in clean water and counterstained with neutral red solution. The slide was then washed in clean water; air dried and observed under microscope with x100 objective lens (oil immersion lens). Gram positive bacteria were observed as blue or purple colour. Gram negative bacteria were observed as red or pink color. The morphology and shape of the bacteria were identified and classification made as cocci, diplococcic, cocci in chains, clusters, rods, etc. 

WITH PREMATURE RUPTURE OF MEMBRANES AT A TEACHING HOSPITAL IN WESTERN

EGrAfure:A sample was inoculated on blood agar, chocolate agar and MaCconkey agar. Then it was incubated both aerobically and anaerobically at $37^{\circ} \mathrm{C}$ for 24-48 hours. Colony morphology was observed according to shape, size, elevation and margin and surface characteristics. Other colony characteristics such as colour, margin, hemolysis on blood agar medium among others were also observed.

\section{1 | Biochemical tests:}

Catalase test: This was done to differentiate between Streptococcus and Staphylococcus species. A drop of $3 \%$ hydrogen peroxide was added to a loop full of the test organisms. Presence of bubbles indicated catalase activity. Streptococcus species is catalase negative while Staphylococcus species is catalase positive (10) (11)

Indole test: A $1 \%$ tryptophan broth in a test tube was inoculated with the isolate and incubated at $37^{\circ} \mathrm{C}$ for 24 hours. After 24 hours, the test tube was shaken gently and 10-15 drops of Kovac's reagent added and red ring on the surface was observed. The formation of red ring coloration at the surface layer indicated a positive test, while a yellow coloration indicated negative result. Escherichia coli and Proteus are indole positive (10) (11).

Urease test: The test organism was inoculated into urease broth and incubated at $37^{\circ} \mathrm{C}$ for 24 hours. Purplish pink coloration of the medium indicated a positive reaction for Proteus and negative for other enterobacteria like Klebsiellaand E. coli (10) (11).

Citrate utilization: This was carried out by inoculating the test organism in test tube containing Simmon citrate medium and incubated for 24 hours at $37^{\circ} \mathrm{C}$. The development of deep-blue color after incubation indicated a positive result. Klebsiella species are citrate positive (10) (11).

Bacitracin test: We inoculated evenly the surface of a plate of blood agar with a culture of the beta haemolytic streptococci to be tested. A disc of bacitracin was then deposited on the inoculated surface and incubated for 24 hours at $37^{\circ} \mathrm{C}$. The presence or absence of an inhibition halo around the disc was observed.

\subsubsection{Mannitol Salt Agar (MSA): This was done following results of Gram's stain and catalase test for the confirmation of Stapylococcus aureus. A plate of sterile MSA was inoculated with a discrete colony of the test organism using a sterile wire loop by making a streak plate method and incubated at $37^{\circ} \mathrm{C}$ for 24-48 hours. Staphylococcus aureus being a salt tolerant organism fermented Mannitol giving golden yellow colonies.}

Oxidase test: A filter paper soaked with the substrate tetramethyl-p-phenylenediaminedihydrochloride was moistened with sterile distilled water. Using a glass rod, a colony of the test organism was smeared on the filter paper. The development of a blue-purple color within ten seconds was indicative of positive test while absence or formation of a blue-purple color after ten seconds was considered negative (10). Pseudomonas species and Neisseria species are oxidase positive (10) (11).

Susceptibility tests : The susceptibility pattern of the identified pathogens was determined by agar disc diffusion technique as described by Kirby-Bauer using Muller Hinton agar. The Muller Hinton agar was prepared according to the manufacturer instructions under sterile conditions to avoid any contamination that would result. Four to five colonies of the organism were diluted in sterile peptone water, mixed and incubated for 4-5 minutes and its turbidity compared to a McFarland standard $0.5 \%$. A prepared Muller Hinton agar was warmed and dried in an incubator for at least 15 minutes. Using a sterile glass rod or swab stick, the surface was smeared with the diluted organism of the peptone water. Using sterile forceps, 11 different antibiotic discs (Amikacin 30 $\mu \mathrm{g}$, Amoxicillin $10 \mu \mathrm{g}$, Ampicillin $10 \mu \mathrm{g}$, Azithromycin $15 \mu \mathrm{g}$, Cefixime $5 \mu \mathrm{g}$, Ceftriaxone $30 \mu \mathrm{g}$, Cloxacillin $30 \mu \mathrm{g}$, Erythromycin $15 \mu \mathrm{g}$, Gentamicin $10 \mu \mathrm{g}$, Imipenem $10 \mu \mathrm{g}$ and Nitrofurantoin $300 \mu \mathrm{g}$ ) were placed on the dried surface of the Muller Hinton agar on $150 \mathrm{~mm}$ plate containing the organism and then placed in the incubator at $37^{\circ} \mathrm{C}$ for 24 hours. A clear zone surrounding the antibiotic disc was measured in millimeters and compared to a standard antibiotic chart for measuring zone of inhibition. The zone of inhibition measured was recorded as susceptible (S), Intermediate (I), and Resistant (R) according to the 


\section{MANUSCRIPT CENTRAL}

standard chart(10).

\section{4 | DATA ANALYSIS}

Data was imported into STATA version 14.2 and percentages were computed for each of the individual bacteria isolates. This was presented in form of a bar graph. Percentages were computed for each of the individual bacteria isolates which are; Sensitive, Intermediate and Resistant. This was presented in form of tables.

\section{5 | RESULTS}

Growth of Common bacterial pathogens in women with PROM at KIU-TH $(n=46)$.

Out of 334 pregnant mothers enrolled in the study, $46(13.8 \%)$ had premature rupture of membranes and therefore had their samples taken for culture and susceptibility testing. Of these, 27(58.7\%) showed growth of the different bacterial pathogens. We registered no growth in the other $19(41.3 \%)$ patients with PROM. This is shown inFigure 1.

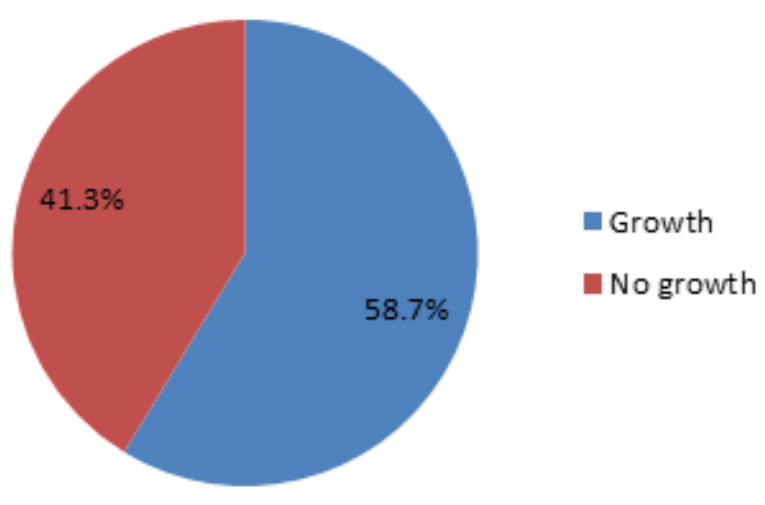

FIGURE 1: Growth of Common bacterial pathogens in mothers with PROM at KIU-TH

\subsection{Common bacterial pathogens in mothers with PROM at KIU-TH ( $n=27)$.}

Out of the 27 bacterial growths from mothers with premature rupture of membranes, the most common were Staphylococcus aureus 8(29.6\%), followed by Escherichia coli and Neisseria gonorrhoeae, each $7(25.9 \%)$. This is shown inFigure 2.

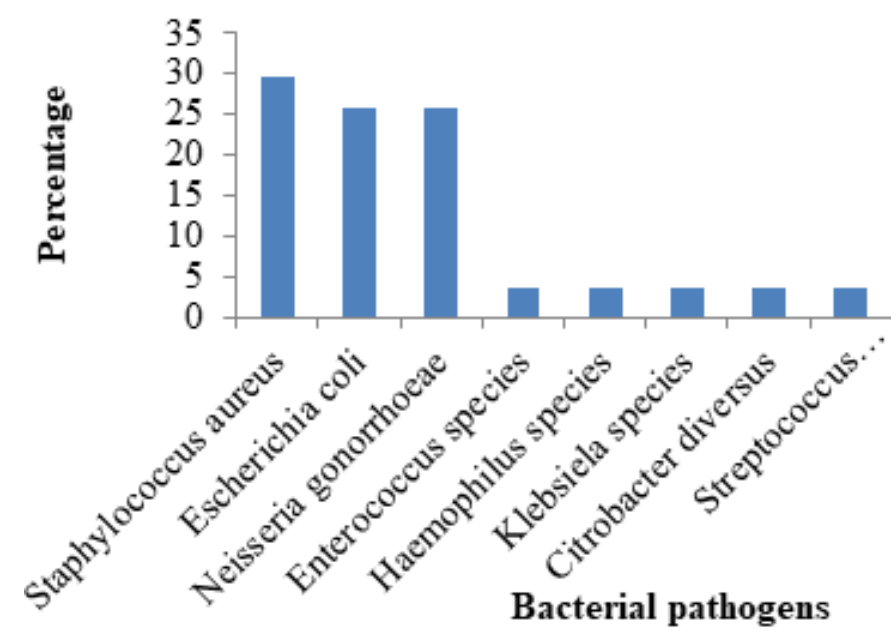

FIGURE 2: Bacterial pathogens in mothers with premature rupture of membranes at KIU-TH.

\subsection{Antibacterial susceptibility patterns of the bacterial pathogens isolated from women with PROM at KIU-TH.}

\subsection{1 | Sensitivity to antibacterial drugs}

All the bacterial growths were sensitive to imipenem $27(100.0 \%)$ and this was followed by nitrofurantoin 25(92.6\%), cloxacillin 23(85.2\%) and azithromycin $22(81.5 \%)$. Staphylococcus aureus showed highest sensitivity to nitrofurantoin and imipenem each at $8(100.0 \%)$, followed by cloxacillin $6(75.0 \%)$. E. coli showed highest sensitivity to imipenem $7(100.0 \%)$, followed by amikacin, nitrofurantoin and azithromycin, each 6(85.7\%). Neisseria gonorrhoeae showed total sensitivity to imipenem, cloxacillin, and azithromycin each at $7(100.0 \%)$. This is shown in table 1.

\subsection{2 | Table 1: Sensitivity to antibacterial drugs}

Staph aureus $=$ Staphylococcus aureus, N.gonorhoeae = Neisseria gonorrhoeae, Strep agalactiae = Streptococcus agalactiae. Cefi = Cefixime, Erythro $=$ Erythromycin, Azithro $=$ Azithromycin, Clox $=$ Cloxacillin, Imip = Imipenem, Amika = Amikacin, Nitro $=$ Nitrofurantoin, Genta $=$ Gentamycin . 
BACTERIAL PATHOGENS AND THEIR SUSCEPTIBILITY TO ANTIBIOTICS AMONG MOTHERS WITH PREMATURE RUPTURE OF MEMBRANES AT A TEACHING HOSPITAL IN WESTERN

WABAEYPSensitivity to antibacterial drugs

\begin{tabular}{lcccccccc} 
Sensitivity & Cefi & $\begin{array}{l}\text { Ery- } \\
\text { thro }\end{array}$ & Azithro & Clox & Imip & Amika & Nitro & Genta \\
$\begin{array}{l}\text { Staph aureus } \\
(n=8)\end{array}$ & $3(37.5)$ & $0(0.0)$ & $5(62.5)$ & $6(75.0)$ & $8(100.0)$ & $5(62.5)$ & $8(100.0)$ & $1(12.5)$ \\
$\begin{array}{l}\text { E. coli } \\
(n=7)\end{array}$ & $1(14.3)$ & $2(28.6)$ & $6(85.7)$ & $5(71.4)$ & $7(100.0)$ & $6(85.7)$ & $6(85.7)$ & $2(28.6)$ \\
$\begin{array}{l}\text { N. gonorrhoeae } \\
(n=7)\end{array}$ & $3(42.9)$ & $0(0.0)$ & $7(100.0)$ & $7(100.0)$ & $7(100.0)$ & $4(57.1)$ & $6(85.7)$ & $0(0.0)$ \\
$\begin{array}{l}\text { Enterococcus spp } \\
(n=1)\end{array}$ & $0(0.0)$ & $0(0.0)$ & $1(100.0)$ & $1(100.0)$ & $1(100.0)$ & $1(100.0)$ & $1(100.0)$ & $0(0.0)$ \\
$\begin{array}{l}\text { Haemophilus spp } \\
(n=1)\end{array}$ & $0(0.0)$ & $0(0.0)$ & $1(100.0)$ & $1(100.0)$ & $1(100.0)$ & $1(100.0)$ & $1(100.0)$ & $0(0.0)$ \\
$\begin{array}{l}\text { Klebsiella spp } \\
(n=1)\end{array}$ & $0(0.0)$ & $0(0.0)$ & $1(100.0)$ & $1(100.0)$ & $1(100.0)$ & $1(100.0)$ & $1(100.0)$ & $0(0.0)$ \\
$\begin{array}{l}\text { Citrobacterdiversus } \\
(n=1)\end{array}$ & $1(100.0)$ & $0(0.0)$ & $1(100.0)$ & $1(100.0)$ & $1(100.0)$ & $0(0.0)$ & $1(100.0)$ & $0(0.0)$ \\
$\begin{array}{l}\text { Strep agalactiae } \\
(n=1)\end{array}$ & $1(100.0)$ & $0(0.0)$ & $0(0.0)$ & $1(100.0)$ & $1(100.0)$ & $0(0.0)$ & $1(100.0)$ & $0(0.0)$ \\
$\begin{array}{l}\text { Total } \\
(n=27)\end{array}$ & $9(33.3)$ & $2(7.4)$ & $22(81.5)$ & $23(85.2)$ & $27(100)$ & $18(66.7)$ & $25(92.6)$ & $3(11.1)$ \\
\hline
\end{tabular}

\section{Resistance to antibacterial drugs}

As is shown in table 2, all the bacterial growths were resistant to amoxicillin, ampicillin and ceftriaxone at $27(100.0 \%)$. This was followed by gentamycin $20(74.1 \%)$ and erythromycin $19(70.4 \%)$.

\subsection{3 | Table 2: Resistance to antibacterial drugs}

Stapaureus $=$ Staphylococcus aureus, E.coli $=E s-$ cherichia coli, N.gonorrhoeae = Neisseria gonorrhoeae, Strep agalactiae = Streptococcus agalacctiae. Amox $=$ Amoxicillin, Amp = Ampicillin, $\mathrm{Cef}=$ Ceftriaxone, $\mathrm{Cefi}=$ Cefixime, Eryth $=$ Erythromycin, Azith $=$ Azithromycin, Clox $=$ Cloxacillin, Amika $=$ Amikacin, Genta = Gentamcycin.

\subsubsection{Intermediate sensitivity to antibacterial drugs}

Erythromycin expressed the highest intermediate resistance, $6(22.2 \%)$ followed by gentamycin $4(14.8 \%)$. This is shown in table 3.

\subsection{5 | Table 3: Intermediate sensitivity to antibacterial drugs}

Staph aureus $=$ Staphylococcus aureus, N. gonorrhoeae $=$ Neisseria gonorrhoeae, Strep agalactiae = Streptococcus agalactiae, Erythro = Erythromycin, Azithro = Azithromycin, Clox $=$ Cloxacillin, Nitro = Nitrofurantoin, Genta $=$ Gentamycin

\section{6 | DISCUSSION:}

The study while considering individual isolates, $S$ taphylococcus aureus was the most common bacterial pathogen among mothers with PROM at KIUTH. This finding was consistent with that of Zeng et al., (12) in China, Gahwagi et al., (13) in Libya, and Musaba et al., (14) in Mulago hospital in Uganda. Although a prevalence of $13.7 \%$ vaginal colonization with $S$. aureus has been reported by Top et al., (15), this pathogen is a known common component of the human skin microbiota and a major nosocomial and community acquired pathogen which is more likely to occur in individuals with extensive healthcare exposure such as PROM patients. And 


\section{MANUSCRIPT CENTRAL}

TABLE 2: Resistance to antibacterial drugs

\begin{tabular}{llllllllll} 
& Amox & Amp & Cef & Cefi & Eryth & Azith & Clox & Amika & Genta \\
$\begin{array}{l}\text { Stapaureus } \\
(n=8)\end{array}$ & $8(100.0)$ & $8(100.0)$ & $8(100.0)$ & $5(62.5)$ & $6(75.0)$ & $2(25.0)$ & $0(0.0)$ & $3(37.5)$ & $6(75.0)$ \\
$\begin{array}{l}\text { E. coli } \\
(n=7)\end{array}$ & $7(100.0)$ & $7(100.0)$ & $7(100.0)$ & $6(85.7)$ & $3(42.9)$ & $1(14.3)$ & $2(28.6)$ & $1(14.3)$ & $4(57.1)$ \\
$\begin{array}{l}\text { N.gonorrhoeae } \\
(n=7)\end{array}$ & $7(100.0)$ & $7(100.0)$ & $7(100.0)$ & $4(57.1)$ & $6(85.7)$ & $0(0.0)$ & $0(0.0)$ & $3(42.9)$ & $6(85.7)$ \\
$\begin{array}{l}\text { Enterococcus spp } \\
(n=1)\end{array}$ & $1(100.0)$ & $1(100.0)$ & $1(100.0)$ & $1(100.0)$ & $1(100.0)$ & $0(0.0)$ & $0(0.0)$ & $0(0.0)$ & $1(100.0)$ \\
$\begin{array}{l}\text { Haemophilus spp } \\
(n=1)\end{array}$ & $1(100.0)$ & $1(100.0)$ & $1(100.0)$ & $1(100.0$ & $1(100.0$, & $0(0.0)$ & $0(0.0)$ & $0(0.0)$ & $0(0.0)$ \\
$\begin{array}{l}\text { Klebsiellaspp } \\
(n=1)\end{array}$ & $1(100.0)$ & $1(100.0)$ & $1(100.0)$ & $1(100.0)$ & $0(0.0)$ & $0(0.0)$ & $0(0.0)$ & $0(0.0)$ & $1(100.0)$ \\
$\begin{array}{l}\text { Citrobacter diversus } \\
(n=1)\end{array}$ & $1(100.0)$ & $1(100.0)$ & $1(100.0)$ & $0(0.0)$ & $1(100.0$ & $0(0.0)$ & $0(0.0)$ & $1(100.0$, & $1(100.0)$ \\
$\begin{array}{l}\text { Strep agalactiae } \\
(n=1)\end{array}$ & $1(100.0)$ & $1(100.0)$ & $1(100.0)$ & $0(0.0)$ & $1(100.0)$ & $1(100.0)$ & $0(0.0)$ & $1(100.0)$ & $1(100.0)$ \\
$\begin{array}{l}\text { Total } \\
(n=27)\end{array}$ & $27(100.0$ & $27(100.0$ & $27(100.0$ & $18(66.7$ & $19(70.4$ & $4(14.8)$ & $2(7.4)$ & $9(33.3)$ & $20(74.1)$ \\
\hline
\end{tabular}

TABLE 3: Intermediate sensitivity to antibacterial drugs

\begin{tabular}{llllll} 
Bacterial Pathogens & Erythro & Azithro & Clox & Nitro & Genta \\
$\begin{array}{l}\text { Staph aureus } \\
(n=8)\end{array}$ & $2.0(25.0)$ & $1(12.5)$ & $2(25.0)$ & $0.0(0.0)$ & $1(12.5)$ \\
$\begin{array}{l}\text { Escherichia coli } \\
(n=7)\end{array}$ & $2.0(28.6)$ & $0.0(0.0)$ & $0.0(0.0)$ & $1.0(14.3)$ & $1(14.3)$ \\
$\begin{array}{l}\text { N. gonorrhoeae } \\
(n=7)\end{array}$ & $1.0(14.3)$ & $0.0(0.0)$ & $0.0(0.0)$ & $1.0(14.3)$ & $1(14.3)$ \\
\hline $\begin{array}{l}\text { Enterococcus spp (n=1) } \\
\text { Haemophilus spp }\end{array}$ & $0.0(0.0)$ & $0.0(0.0)$ & $0.0(0.0)$ & $0.0(0.0)$ & $0.0(0.0)$ \\
$(n=1)$ & $0.0(0.0)$ & $0.0(0.0)$ & $0.0(0.0)$ & $0.0(0.0)$ & $1(100.0)$ \\
$\begin{array}{l}\text { Klebsiella spp } \\
(n=1)\end{array}$ & $1.0(100.0)$ & $0.0(0.0)$ & $0.0(0.0)$ & $0.0(0.0)$ & $0.0(0.0)$ \\
$\begin{array}{l}\text { Citrobacterdiversus } \\
(n=1)\end{array}$ & $0.0(0.0)$ & $0.0(0.0)$ & $0.0(0.0)$ & $0.0(0.0)$ & $0.0(0.0)$ \\
$\begin{array}{l}\text { Strep agalactiae } \\
(n=1)\end{array}$ & $0.0(0.0)$ & $0.0(0.0)$ & $0.0(0.0)$ & $0.0(0.0)$ & $0.0(0.0)$ \\
$\begin{array}{l}\text { Total } \\
(n=27)\end{array}$ & $6.0(22.2)$ & $1.0(3.7)$ & $2.0(7.4)$ & $2.0(7.4)$ & $4.0(14.8)$ \\
\hline
\end{tabular}




\section{BACTERIAL PATHOGENS AND THEIR SUSCEPTIBILITY TO ANTIBIOTICS AMONG MOTHERS WITH PREMATURE RUPTURE OF MEMBRANES AT A TEACHING HOSPITAL IN WESTERN}

UsG DANDAA et al., (16) suggests, the pathogen is also known to exploit the proinflammatory activity of $\alpha$ hemolysin to promote disruption of vaginal tissue, hence enhancing biofilm formation on the genital tract mucosal surfaces which enables it to overcome host immunity.

Overall however, most of our growths belonged to gram negative bacteria and this was attributed to the nature of these organisms as they are known to inhabit the lower Gastro Intestinal Tract as normal flora and therefore can easily access the vagina to cause ascending infection and consequently lead to PROM. This finding is in line with that of Adewumi et al., (17) in Nigeria where Klebsielawas the commonest bacterial pathogen isolated followed by $E$. coli, Salou et al., (18) in Togo were E. coli was the most common bacterial pathogen isolated, Rani et al., (19) in India whereE. coli was the most common followed by Staphylococcus aureus and Annie et al., (20) also in India where Klebsiellapneumoniae was the most common bacterial isolate followed by Staphylococcus aureus. The discrepancy as regards the most common individual isolates was explained by the difference in techniques used to obtain the samples as these studies used vaginal swabs unlike our study where only endocervical samples were used. This probably minimized the risk of contamination with lower bowel enteric organisms including E. coli.

Secondly, this study found total antibiotic resistance of the bacterial growth isolates from pregnant mothers with PROM was to amoxicillin, ampicillin and ceftriaxone. This was in agreement with Zeng et al., (12) in china who reported similar results, with up to $100 \%$ resistance of staphylococcal species to penicillins. This finding also bears close similarities in the study results of Eleje and colleagues (21) in Nigeria where amoxicillin and ampicillin were the least effective of the antibiotics to bacterial growth isolates. However, cloxacillin was reported to be least effective in their study, which is different from the findings of our study, where cloxacillin was among the most sensitive antibacterial agents despite its exhibition of some intermediate sensitivity to staphylococcus aureus. This might be explained by the slight variation in the individual bacterial isolates and the fact that cloxacilin is rarely prescribed in our study setting and therefore not many microbial pathogens have been exposed to it. Besides cloxacillin, our study also found high sensitivity to imipinem, nitrofurantoin and azithromycin by most bacterial pathogens. These findings are consistent with those of Musaba and colleagues (14) in Mulago hospital where resistance to most commonly used broad spectrum antibiotics such as ceftriaxone, ampicillin, and erythromycin was notably high among the cervicovaginal isolates in women with premature rupture of membranes. In their study, it was only the less commonly used and more expensive antibiotics like vancomycin and meropenem that showed the highest levels of sensitivity to the isolated antibiotics. This similarity may be due to the similar problem of irrational drug use of antibiotics which seems to involve the entire country, Uganda from which this study was also conducted.Staphylococcusaureus which was our most common isolate showed 100\% sensitivity to imipenem and nitrofurantoin, and $100 \%$ resistance to ceftriaxone, amoxacillin and ampicillin. Discrepancy was noted with the findings of Adewumi et al., (17) in Nigeria who found excellent sensitivity with amoxiclav (94.4\%), ceftriaxone $(92.6 \%)$, erythromycin $(88.9 \%)$ and gentamicin $(70.4 \%)$. These variations were attributed to the differences in patterns of drug use among the different study populations.

\section{7 | LIMITATION:}

The number of cases with PROM that we received during the study period, that is, 46 ; were generally small to enable us generalize our conclusions. More so, we had no control group given the fact that this was a cross-sectional study design with minimal financial resources. A bigger study with provision for a control group is therefore highly recommended in the future. Additionally, given the study design, we could not establish the outcomes (either maternal, neonatal or both) of our patients. Further studies with appropriate study designs aimed at ascertaining these aspects are also highly suggested. 


\section{8 | ACKNOWLEDGEMENT:}

We greatly acknowledge and thank all the pregnant mothers who consented to participate in this study for their invaluable time.

\section{Ethical approval :}

This study was approved by the Research Ethics Committee of Kampala International University, approval number UG-REC-023/201925.

\section{9 | REFERENCES:}

1. Shadma K, Aymen AK. Study on preterm pre mature rupture of membranes with special reference to maternal and its fetal outcome. Int J Reprod Contraception, Obstet Gynecol. 2016;5(8):2768-74.

2. Nourossadat K, Maryam A, Mehdi H, Masoumeh F, Hamid AM. Diagnosis of premature rupture of membranes by assessment of urea and creatinine in vaginal washing fluid. Iran J Reprod Med. 2013;11(2):93-100.

3. Cunningham FG, Leveno KJ, Bloom SL, Dashe JS, Hoffman BL, Casey BM. Williams Obstetrics. 25th ed. McGraw-Hill Education; 2018.

4. Kayiga H, Lester F, Amuge PM, Byamugisha J, Autry M. Impact of mode of delivery on pregnancy outcomes in women with premature rupture of membranes after 28 weeks of gestation in a lowresource setting : A prospective cohort study. PLoS One. 2018;991(1):1-13.

5. Birkneh TT, Elizabeth AA, Stefano O, Joshua H, Miranga W, Iveth JG, et al. Antimicrobial resistance in Africa : a systematic review. BMC Infect Dis. 2017;616(17):1-17.

6. UNAS. Antibiotic Resistance in Uganda : Situation Analysis and Recommendations. 2015.

7. MOH U. Uganda Clinical Guidelines. 2016;

8. Daniel WW. Biostatistics. A Foundation for Analysis in the Health Sciences. John Wiley \& Sons, Inc.; 2009.

9. Thomson AJ. Care of Women Presenting with Suspected Preterm Prelabour Rupture of Membranes from $24+0$ Weeks of Gestation. BJOG. 2019;126(73):152-66.
10. Cheesbrough M. District laboratory practice in tropical countries. Vol. Part 1, District laboratory practice in tropical countries Part 2. 2006. 442 p.

11. Connie RM, Donald CL, George M. Textbook of diagnostic microbiology. 5th ed. Maryland Heights, Missouri.: Saunders, Elsevier.; 2015.

12. Zeng L, Zhang L, Shi J, Gu L, Grogan $\mathrm{W}$, Gargano MM, et al. The primary microbial pathogens associated with premature rupture of the membranes in China: A systematic review. Taiwan J Obstet Gynecol. 2014;53(4):443-51.

13. Gahwagi MMM, Busarira MO, Atia M. Premature Rupture of Membranes Characteristics , Determinants, and Outcomes of in Benghazi, Libya. Open J Obstet Gynecol. 2015;5(8):494-504.

14. Musaba MW, Kagawa MN, Kiggundu C, Kiondo P, Wandabwa J. Cervicovaginal Bacteriology and Antibiotic Sensitivity Patterns among Women with Premature Rupture of Membranes in Mulago Hospital , Kampala , Uganda : A Cross-Sectional Study. Infect Dis Obstet Gynecol. 2017;2017(6):1-7.

15. Top KA, Buet A, Whittier S, Ratner AJ, Saiman L. Predictors of staphylococcus aureus rectovaginal colonization in pregnant women and risk for maternal and neonatal infections. J Pediatric Infect Dis Soc. 2012;1(1):7-15.

16. Doster RS, Kirk LA, Tetz LM, Rogers LM, Aronoff DM, Gaddy JA. Staphylococcus aureus Infection of Human Gestational Membranes Induces Bacterial Biofilm Formation and Host Production of Cytokines. J Infect Dis. 2017;215(4):653-7.

17. Adewumi O, Olofinbiyi B, Oyekale O, Loto O, Abu S, Sotunsa OJ. Microbiological Pattern in Preterm Prelabour Rupture of the Fetal Membranes in South-Western Nigeria. Obstet Gynecol Int Journal. 2017;6(4):4-10.

18. Salou M, Lack F, Adama-hondegla AB, Dossim S, Tsogbalé N, Gbadoé A. Premature Rupture of the Membranes at the Sylvanus Olympio University Hospital of Lomé , Togo : Microbiological Findings and Outcomes. Am J Infect Dis Microbiol. 2015;3(6):152-6.

19. Rani S, Mehra R, Gupta V, Huria A, Chander J. Vaginal flora in preterm premature rupture of membranes and their sensitivity to commonly used 
BACTERIAL PATHOGENS AND THEIR SUSCEPTIBILITY TO ANTIBIOTICS AMONG MOTHERS WITH PREMATURE RUPTURE OF MEMBRANES AT A TEACHING HOSPITAL IN WESTERN

untibinicA. Asian J Med Sci. 2014;5(4):58-60.

20. Annie R, Thomas SK, Sarah J, Neha MB. Microbiological Profile of PROM in a Tertiary Care Centre in Mangalore,Karnataka State. Int J Heal Sci Res. 2014;4(October):72-6.

21. Eleje G, Adinma JJ, Ghasi S, Ikechebelu JJ, Igwegbe OA, Okonkwo EJ, et al. Antibiotic susceptibility pattern of genital tract bacteria in pregnant women with preterm premature rupture of membranes in a resource-limited setting. Int J Gynecol
Obstet. 2014;1(3):7-11.

How to cite this article: Byonanuwe S., Nzabandora E., Nyongozi B., Pius T., Fajardo Y., Ssebuufu R. Bacterial Pathogens and their Susceptibility to Antibiotics among Mothers with Premature Rupture of Membranes at a Teaching Hospital in Western Uganda.. Journal of Medical Care Research and Review. 2020;386-394. https://doi.or $\mathrm{g} / 10.15520 /$ mcrr.v3i7.106 